\title{
EL PODER CIUDADANO EN LA GOBERNANZA DEL SISTEMA ANTICORRUPCIÓN DE MÉXICO
}

\author{
Rafael Enrique Valenzuela Mendoza \\ Universidad Autónoma de Ciudad Juárez, México \\ rafael.valenzuela1@gmail.com
}

\section{RESUMEN}

El objetivo del artículo es discutir el rol de la participación ciudadana en el combate a la corrupción, a partir de la reciente creación del Sistema Nacional Anticorrupción (SNA) en México. En específico, centra su atención en los comités de participación ciudadana, como vía institucionalizada en el SNA. El estudio afirma que la participación ciudadana tiene implicaciones en el combate a la corrupción, pero es insuficiente si no se acompañe de otros ingredientes que fortalezcan la gestión de la participación ciudadana en el SNA.

Palabras clave: Corrupción, Participación ciudadana, Sistema Nacional Anticorrupción, México. 


\title{
CITIZEN POWER AND GOVERNANCE OF MEXICO'S ANTI-CORRUPTION SYSTEM
}

\begin{abstract}
The purpose of this paper is to discuss the role of citizen participation in the combat of corruption in light of the creation of the National Anti-Corruption System in Mexico. Specifically, it focuses on the citizen participation committees as an institutional mechanism within the SNA. The study asserts that citizen participation has implications for combatting corruption, but is insufficient if not accompanied by other elements that strengthen management of citizen participation in the SNA.
\end{abstract}

Keywords: Corruption, citizen participation, National Anti-Corruption System, Mexico. 


\section{INTRODUCCIÓN}

El objetivo del artículo es poner a discusión el rol de la participación ciudadana en el combate a la corrupción, dentro del recientemente creado Sistema Nacional Anticorrupción (SNA) en México. A tres años de su existencia, el SNA tiene como finalidad generar coordinación entre todos los entes públicos responsables de combatir la corrupción. Su articulación se finca en dos Comités: el Comité de Participación Ciudadana (CPC) formado por cinco ciudadanos y el Comité Coordinador integrado por entidades de gobierno y organismos autónomos que tienen la función de prevenir y sancionar actos o hechos de corrupción. Para resolver el problema de la coordinación el SNA incorpora a ciudadanos fuera del servicio público, y ahí aparece el primer gran reto, que consiste en conocer si los ciudadanos tendrán el poder suficiente para lograr la coordinación de los entes de gobierno responsables de combatir la corrupción.

El SNA se constituye con la finalidad de alcanzar el mayor nivel de coordinación posible, la Presidencia de todo el Sistema recae en el Presidente del CPC. El poder ciudadano está ubicado como cabeza de un sistema creado contra la corrupción en México. En la primera parte del artículo se discute lo conceptual del problema de la corrupción; la segunda parte pone a discusión la cuestión acerca de ¿dónde está hoy el poder?, bajo la idea de abordar en la siguiente parte la relación entre el Estado y la participación ciudadana a partir de una serie de implicaciones que resultan en el combate a la corrupción.

Para abordar la experiencia del SNA en México, se describe su estructura y funcionamiento, pero también se describe el antecedente a partir del movimiento social y posterior iniciativa denominada 3 de 3 , puerta de entrada para debatir el rol del poder ciudadano en la gobernanza de todo un sistema nacional que se propone promover profundos cambios en las políticas anticorrupción, crear una nueva cultura de participación ciudadana y de rendición de cuentas desde el gobierno, pero especialmente rendir cuentas desde los espacios ciudadanos hacia la sociedad civil.

\section{LA CORRUPCIÓN COMO PROBLEMA PÚBLICO}

Entender la corrupción como fenómeno multicausal, complejo y que funciona en redes de actores y grupos, requiere establecer los alcances de esas redes, la eficacia de las acciones de las autoridades, y elaborar planes y programas para la prevención. De este modo, determinar si la corrupción es causa de otros problemas, o si es efecto que deriva en otros fenómenos asociados, será fundamental. Pocas veces se aborda como un conjunto 
de problemas interconectados entre si, donde cada uno tiene sus propias causas y efectos.

En el ámbito de las ciencias sociales no existe una sola definición de corrupción. La más recurrente indica que se trata del "mal uso del cargo público para beneficio privado" (Solaz et al 2019: 897). Bratu and Kazoka (2018) sugieren que definir la corrupción es tarea que se complica por el universo semántico de este concepto, al estar relacionado con otros conceptos adicionales, cuyos significados se superponen en buena parte con la corrupción. Es el caso de conceptos como clientelismo, patronazgo, captura del Estado, patrimonialismo, entre otros (Bratu and Kazoka 2018: $58)$.

La corrupción es un concepto observable solo en su resultado, es oscuro durante el proceso en el cual ocurre y en consecuencia, de difícil observación. Las acciones que la originan no admiten exposición a la luz de lo público, no son susceptibles de transparentarse porque serían motivo de sanción o castigo. Sus causas son diversas, pero es posible definir la corrupción como resultado del abuso del poder público para producir un beneficio privado. Esta definición acuñada por Transparencia Internacional es retomada por Casar (2016 11-12) y robustecida cuando se reconoce en términos de "... abuso de cualquier posición de poder, pública o privada, con el fin de generar un beneficio indebido a costa del bienestar colectivo o individual".

Lo anterior no implica necesariamente que la corrupción se debe concebir únicamente como actos cometidos por individuos en el ámbito de lo público, sino que ocurre en lo privado y no son hechos aislados de un contexto social (Casar 2016: 45). La corrupción debe ser ubicada en el marco de un sistema político que la tolera porque cuenta con engranes que se ajustan a este fenómeno. Limitar el abuso y mal uso de cargos públicos mediante los controles y monitoreo ciudadano que denuncie el beneficio privado, se perfila como línea concreta de participación ciudadana contra la corrupción. Bankole (2015) define corrupción como cualquier acción u omisión promulgada por un miembro de una organización, que va en contra de las reglas, regulaciones, normas y ética de la organización, y el propósito es cumplir con el fin egoísta del miembro en detrimento de la organización (Bankole 2015: 1).

Definir la corrupción en términos de enfermedad social, es un recurso heurístico que tiene algunas características puntuales: 1) se trata de una enfermedad incurable y/o terminal; 2) su sanación es de largo alcance; y 3) es estigmatizada (Bratu and Kazoka 2018: 63). Esta enfermedad resulta contagiosa y produce síntomas como las arbitrariedades en el servicio público, mal uso de la discrecionalidad en los puestos, y la captura de los 
presupuestos de la administración pública por grupos e individuos afines a la corrupción. Klitgard (1998: 336) identifica que las instituciones y las agencias se enferman de corrupción, y los síntomas son débil acceso a la información pública, incentivos ineficaces y la falta de compromiso laboral del servidor público. Sugiere Klitgaard (1998) que la corrupción y el favoritismo no son hechos aislados sino una normalización corrosiva, ocasionada por un bajo salario que se convierte en incentivo de los empleados a buscar otras formas de compensación no salariales y pagos ilícitos por hacer (o no hacer) sus deberes públicos.

Otros síntomas de la corrupción se encuentran en los efectos y consecuencias que tienen la captura de la mayor parte de los puestos públicos en beneficio de un grupo o élite, los cuales terminan por vincular los puestos públicos capturados a decisiones de autoridad en beneficio de unos cuantos, y el ejercicio discrecional de los presupuestos públicos, que deberían estar al servicio de la sociedad (Merino 2013: 140).

La débil posición en la cual el Estado se relaciona con el mercado y la economía, sugiere que la corrupción tiene bases más profundas y de relaciones estructurales de poder entre actores. Mientras el poder del Estado está siendo redistribuido en la sociedad civil, el poder económico está siendo concentrado, ocasionando que "la opacidad que prevalece dentro del sector privado a cargo de la provisión de servicios públicos, no parece estar encaminada a la creación de mercados más eficientes, sino a proteger los intereses de los actores del mercado" (Sandoval 2016: 402).

La corrupción tiene un enfoque estructural que reconoce la complejidad del problema como algo que no es exclusivo del sector público. El enfoque de la corrupción estructural "aboga por extender los controles de transparencia y combate a la corrupción, normalmente reservados para fiscalizar el gobierno y el sector público, hacia el ámbito de las corporaciones y el sector privado" (Sandoval 2016: 367). La corrupción estructural se define como "una forma específica de dominación social sustentada en un diferencial de poder estructural en la que predominan el abuso, la impunidad y la apropiación indebida de los recursos necesarios para el bienestar social y el desarrollo de los derechos fundamentales" (Sandoval 2015: 123, Sandoval 2016: 370).

Por otra parte, Uvalle (2018: 72) define la corrupción en términos de un problema estructural que daña las reglas, procedimientos y líneas de responsabilidad, así como a las instituciones y en consecuencia, a la institucionalidad del poder. Señala además, que la corrupción es un conjunto de prácticas destructivas y nocivas que dañan el desempeño de la sociedad y la economía, al dilapidar la riqueza de la sociedad y el 
intercambio de bienes y servicios.

En las relaciones de antaño la corrupción tenía solo dos actores, uno político -en tanto funcionario de gobierno denominado corrupto- y otro ubicado en el sector privado o social, conocido como corruptor. La sanción era fijada solamente para el corrupto, pero con las reformas legislativas en México, eso ha cambiado. Hoy en día se ha ido aceptando que la corrupción se origina tanto en el sector público, como en el privado. Todas las anteriores definiciones no alcanzan a puntualizar que la corrupción es una red de intereses organizados para dominar la esfera de la política, la economía y la sociedad, para producir beneficios no legítimos. Esta red conecta sus nodos entre sí para establecer un conjunto de beneficios indebidos en términos legales, éticos o sociales.

Esta red de relaciones que operan a favor de la corrupción, constituyen una forma específica de dominación política, falta de regulación económica o violencia social, donde tales relaciones asimétricas se traducen en la reducción de los beneficios sociales, en la claudicación al mejoramiento económico y la restricción del acceso a la arena donde se toman las decisiones públicas. El corrupto puede surgir desde las burocracias públicas, pero también de las burocracias creadas en organizaciones privadas.

La corrupción es un conjunto de problemas sistémicos, interconectados entre si y de carácter público. Sus manifestaciones y expresiones son de distinta naturaleza. Pocas veces se le asume como un concepto que admite diversas dimensiones, y menos se comprende como red de problemas. Montes (2019) señala que

Cuando hablamos de corrupción nos podemos referir al mismo tiempo al soborno que un automovilista ofrece a un oficial de tránsito para evitar una infracción, al financiamiento ilegal de una campaña electoral, a la creación de una empresa fantasma cuyo único objetivo es simular operaciones de contrataciones públicos, a la colusión de empresas contratistas del gobierno que se ponen de acuerdo para simular competencia y maximizar sus ganancias, entre muchos otros ejemplos más (Montes 2019: 2).

Lo anterior implica que corrupción es una red de problemas públicos y afecta de manera transversal a la administración pública (corrupción administrativa), en el ámbito operativo o directivo. Es transversal a la división clásica de tres poderes, Legislativo, Ejecutivo y Jurisdiccional (corrupción política). La corrupción administrativa se refiere principalmente a los actos de la administración pública que afectan el interés general, los cuales son 
realizados por el particular y servidores públicos. Ethos (2017: 12) indica que la corrupción política se manifiesta cuando los "políticos desvían fondos públicos, extorsionan a individuos y/o empresas para obtener recursos, aceptan sobornos para realizar operaciones ilícitas o agilizar otras, compran votos en las elecciones" (Ethos 2017: 12). La corrupción es una representación que explica de manera sencilla un fenómeno complejo de problemas interconectados.

La corrupción se sostiene por una vasta red de actores y organizaciones que tienen el interés de cuidar los beneficios obtenidos, de lo cual se infiere, que la corrupción tiene su origen en cualquier nodo del sector público, del sector privado o social. La literatura especializada describe la corrupción en esos nodos a partir del indicador de su tolerancia, donde destacan dos grupos principales: 1) ciudadanos que la toleran de forma consistente brindando apoyo a políticos corruptos y evadiendo el castigo social por la estructura de valores que predomina; y 2) ciudadanos que la toleran por la existencia de condiciones para beneficiarse de la propia corrupción (Pozsgai 2015: 102). La tolerancia es posible, si existen ambientes de corrupción y bajos costos de cometer acciones como soborno con los cuales se obtienen contratos, se desvían recursos públicos, y se evaden sanciones penales o administrativas mediante pagos a servidores públicos, entre otras expresiones.

\section{¿DÓNDE ESTÁ HOY EL PODER?}

Para transformar los ambientes de corrupción en ambientes de integridad pública, es imprescindible conocer dónde está el poder de lo público. El poder está redistribuido en distintos grupos y coaliciones promotoras que buscan ingresar de temas a la agenda pública. El surgimiento de las nuevas tecnologías digitales, la aparición de medios de comunicación con línea editorial propia, la sustitución paulatina de la idea de gobernado por ciudadano, las alternancias políticas, la apertura de economías en distinta escala, la migración continental e intercontinental, entre otros fenómenos de principios del siglo XXI, desnudaron a un Estado sin capacidades suficientes para enfrentar nuevas y complejas realidades que no tienen referente cercano en el tiempo. El Estado se vio rebasado, mostrando que no puede resolverlo todo por sí mismo, requiere de ciudadanos que colaboren en identificar problemas colectivos.

Durante la década de los noventas, el Estado mexicano redujo su tamaño mediante la venta de empresas y promovió un conjunto de reformas que llevaron al gobierno a la pérdida de muchas de sus competencias legales y constitucionales. Tales competencias y atribuciones fueron absorbidos paulatinamente por organismos públicos autónomos (OCAs) para el 
cumplimiento de tales funciones. De este modo, se configuró una división de poderes donde los OCAs garantizaban el respeto de los derechos de participación de ciudadanos en el proceso decisional del Estado.

La desconfianza ciudadana hacia la función ejecutiva del Estado mexicano, generó "esta nueva imagen del Estado como problema fue en parte consecuencia de su fracaso en cumplir las funciones que le habían fijado" (Evans 2007: 17). Se hizo necesario que procesos de decisión salieran del ámbito de competencia del Ejecutivo para trasladar tales funciones a otras arenas, dejando así de ser el árbitro de algunas materias como la electoral, transparencia, regulador de la economía, entre otras, con el propósito de ganar legitimidad política. Un Estado mexicano que pierde su capacidad interventora de la economía, ahora debe involucrar a otros actores para intervenir menos y regular la actividad de empresas y ciudadanos involucrados en los procesos decisorios, antes reservado de manera exclusiva al Estado. El poder ahora está redistribuido en una amplia red de grupos, actores, coaliciones, medios de comunicación y organizaciones sociales que configuran la decisión de lo público.

Cuando el poder estuvo concentrado en el welfare state, las políticas públicas se definieron con ausencia de la participación ciudadana. Solo era necesaria la participación para legitimar decisiones que previamente estaban tomadas. Eso explica la definición predominante de política pública durante la segunda mitad del siglo XX, que excluía el componente de la participación ciudadana. Las políticas públicas se entendían como "todo lo que el gobierno decide hacer o no hacer" (Dye 1972: 2).

El poder hoy se redistribuye en tres esferas, el Estado, el mercado y la sociedad civil, con fuertes implicaciones en la definición de políticas públicas, las cuales buscan generar mecanismos de corresponsabilidad entre gobierno y sociedad civil. Aguilar (2015) define la política pública como "un conjunto de acciones estructuradas en modo intencional y causal, que se orientan a realizar objetivos considerados de valor para la sociedad o a resolver problemas cuya solución es considerada de interés o beneficio público". Por tanto se pueden inferir que algunos elementos de política pública (public policy) que involucran la participación de ciudadanos, son:

- El conjunto de decisiones de políticas son sistemáticas y causales, porque se orientan a cumplir un objetivo a través de todo el proceso de la política. Esto es, la identificación de los problemas públicos, la gestión de sus alternativas de solución, su implementación y evaluación.

- $\quad$ Los procesos de toma de decisiones influenciados por la sociedad civil en la definición de marcos éticos, legales, políticos y tecnológicos que 
generan mayor certidumbre y confianza institucional, pero también delimitan el conflicto en arenas especificas donde se disputa cual es el problema crítico que debe atender el gobierno.

- $\quad$ El enfoque de gobernar por políticas viene sustituyendo el enfoque de gobernar por planes, que implica nuevas interacciones entre el gobierno y la administración pública con ciudadanos que cuentan con más capacidades, recursos y habilidades.

No obstante la participación de ciudadanos en las políticas, la corrupción permea y se manifiesta en un efecto nocivo en las relaciones entre el gobierno y sus ciudadanos. La corrupción tiene expresiones en la captura del Estado, patrimonialismo, apropiación de rentas del Estado y gobierno como botín, conceptos que guían hacia la comprensión del problema denominado corrupción.

\section{EL ESTADO Y LA PARTICIPACIÓN CIUDADANA}

Por décadas, y en diversos países, se asoció el fenómeno de la corrupción a la naturaleza del gobierno autoritario que ejerció la represión frente a protestas ciudadanas que buscaron la democratización del Estado, llevando incluso a la desaparición forzada ${ }^{1}$ de quienes disentían de los grupos o élites gobernantes. En muchos países, el poder concentrado del Estado fue utilizado para reprimir, hecho que paulatinamente desaparece en la medida que la democracia aflora como resultado de la elevada intensidad de la participación ciudadana en los asuntos públicos. Se asumió que gobiernos electos democráticamente harían desparecer sin dificultad la corrupción.

Los gobiernos electos de forma democrática, visibilizaron ante la sociedad las débiles capacidades del Estado en el control de la agenda pública. De este modo, el Estado debió aumentar sus capacidades mediante el control de los temas de la agenda política y económica, fortaleciendo la capacidad de filtrar temas que suben a la agenda de gobierno (O'Donnell 2008). La democratización del espacio público provocó que el Estado abriera canales de participación ciudadana para convertirse en ancla indispensable de los derechos de la ciudadanía.

Sin este anclaje un régimen democrático simplemente no existe, o se convierte en una caricatura en la que se realizan elecciones, pero ellas no satisfacen requisitos mínimos de competitividad, equidad e institucionalización (O’Donnell 2008: 4).

1 En México la desaparición forzada es un delito contra los derechos humanos que está previsto en el ordenamiento jurídico. 
Un Estado democrático, débil y rebasado por múltiples problemas como la corrupción y la violencia, no le conviene a la sociedad civil, ni a la economía (mercado). El fortalecimiento de un Estado democrático se dará mediante la participación ciudadana. La suma de capacidades ciudadanas y la inteligencia colectiva, sugiere que el Estado puede mejorar su desempeńo si promueve la participación ciudadana institucionalizada y no institucionalizada. Las múltiples definiciones y tipologías de participación ciudadana, sugieren que la participación es un asunto complejo, no es un ente monolítico, requiere de fuerte dosis de liderazgo y legitimidad instrumental. Olvera (2009 citando a Isunza 2006), señala que la participación se entiende como

[...] la intervención organizada de ciudadanos individuales o de organizaciones sociales y civiles en los asuntos públicos, que se lleva a cabo en espacios y condiciones definidas, esto es, en interfaces socioestatales (Olvera 2009).

De la anterior definición como intervención, se acude a la acuñada por Montes de Oca (2014: 292), quien la define en términos de un mecanismo que, idealmente, garantice control e influencia sobre el actor gubernamental que opera en forma de red. Una mirada desde el enfoque de redes, facilita el entendimiento como un mecanismo facilitador que funciona mediante intercambio de información pública. Siguiendo a Montes de Oca (2014), cuando la red funciona dentro de la estructura de gobierno, la participación se denomina paragubernamental, y cuando está ubicada por fuera de la estructura de gobierno, se denomina extragubernamental.

Ejemplo de los primeros son las oficinas de contraloría social, las entidades colegiadas orientadas a asesorar y opinar sobre la toma de decisión pública (comités o consejos consultivos), las instancias de seguimiento de programas sociales, o los mecanismos participativos para la gestión de presupuestos locales. Los observatorios ciudadanos, los conglomerados de organizaciones civiles o los think tanks, que monitorean desde fuera el quehacer del gobierno, son muestra de redes que operan en espacios extragubernamentales (Montes de Oca 2014: 292).

Estas definiciones de Montes de Oca (2014) sugiere la importancia de identificar una tipología de la participación ciudadana. Para lograr perfilar alguna tipología, Aguirre (2013) explica que la diferencia entre participación política y ciudadana es únicamente de grado. La participación política se efectúa por los ciudadanos y está acotada a instituciones formales. Se rige por leyes y reglamentos. Por ejemplo, la constitución de partidos políticos, 
el acto de votar, formar parte de comisiones o cabildos, ejercer funciones públicas en comités ciudadanos o consejo consultivos, entre otros. De esta manera, la participación política constituye una acción que está definida y acotada mediante normas del Estado. Es equivalente a una participación ciudadana institucionalizada, sea individual o colegiada (colectiva). Corresponde a lo que Montes de Oca (2014) denominó participación ciudadana paragubernamental. Su función es la vigilancia social por canales institucionalizados.

Por otra parte, la participación ciudadana que se limita a la búsqueda de la interacción con el Estado en la arena pública, tiene como propósito influir sobre él en la definición de políticas públicas y, en el mejor de los casos, generar movimientos para el reconocimiento de nuevos derechos. Este tipo de participación extragubernamental, puede estar organizada en asociaciones formales y permanentes, o bien, solo estar agrupada en coaliciones o colectivos temporales que desaparecen cuando se cumple el objetivo por el cual fueron creados.

Aquí conviene establecer que se entiende por asociación u organización de la sociedad civil (OSC), y se define como el conjunto de

[...] organizaciones privadas y relativamente autónomas que proveen a sus miembros y no miembros de bienes o servicios, que están públicamente registradas (tienen personalidad jurídica) y están subsidiadas por donaciones voluntarias, más que por ingresos derivados de un intercambio comercial, cuotas o votos. Las fuentes de financiamiento generalmente provienen de otras organizaciones no gubernamentales (Somuano 2010: 220).

De igual forma, también existen OSC que reciben financiamiento público, según sea su objeto de creación. Estos actores sociales vinieron a darle una bocanada de aire a los sistemas políticos latinoamericanos y fueron clave en los procesos de democratización. No fueron pocos los movimientos sociales que demandaban reconocimiento de algún derecho o la prestación de servicios, las que se constituyeron en OSC. Esto fue preámbulo de la ciudadanización de los temas electorales (participación política), de salud, de educación y más recientemente, en el combate a la corrupción (participación ciudadana). "La participación política ejerce la democracia, mientras la participación ciudadana la genera y la amplía. La primera es una participación acotada en la medida en que se encuentra institucionalizada; la segunda no está acotada" (Aguirre 2013: 124).

La ciudadanía tiene dos grandes esquemas, de acuerdo con el resultado 
obtenido en su participación: resultados no vinculantes y resultados vinculantes. El primero, refiere a las consultas, formulación de opiniones o elaboración de propuestas de mejora para la acción del gobierno. La autonomía del ciudadano es factor clave para incidir en la esfera pública.

La participación bajo esquemas vinculantes a la acción del Estado, resulta relevante cuando el ciudadano posee habilidades técnicas (legitimidad instrumental), pero también legitimidad política (reconocimiento de actores políticos). Esto implicará que en su designación se producto de un proceso de selección transparente y participativo, para integrar el organismo o instancia ciudadanizada que corresponda.

De este modo, la existencia de OCAs ciudadanizados cuyas determinaciones no son vinculantes, terminan por emitir recomendaciones con efectividad supeditada al liderazgo del ciudadano o a la buena voluntad del Estado para dar cumplimiento al asunto en concreto. Los OCAs ciudadanizados cuyas determinaciones si son vinculantes, resultan en insumo de políticas públicas. Este tipo de participación deberá contar con un efectivo diseño institucional que arrope la actuación de los ciudadanos y facilite el cumplimiento de sus determinaciones.

Otro insumo en torno de una tipología que agrupe las diversas formas de participación ciudadana, corresponde la naturaleza de la participación. Ésta se mueve en el eje definido por la naturaleza conflictiva, colaborativa y la irruptiva. En la primera, se reconoce el conflicto está presente de forma inherente a ciudadanos que asumen la búsqueda del control social sobre el gobierno. Ello implicará la interacción ciudadana basada en lógicas de desconfianza hacia la actuación gubernamental. La participación ciudadana que busca el control social genera conflicto, pero es opuesta a la idea de participar para desmantelar al Estado o dinamitar estructuras de gobierno, ya que la primera está en pro de consolidar y fomentar la capacidad de filtrar fenómenos como la corrupción. Los modelos de rendición de cuentas están basados en la desconfianza, y son los que operan en esta lógica para exigir mejor desempeño del Estado o el gobierno.

La colaboración, segunda forma de participación, implicará propuestas de política pública y el diseño conjunto de estrategias para gestionar con los ciudadanos soluciones a problemas de gobernanza democrática. Las relaciones presentan distintos grados de confianza en la interacción que se propone abrir gobiernos para incentivar el acceso de ciudadanos a la arena de la toma de decisiones.

En cambio, la participación irruptiva, refiere a una forma de participación ciudadana antisistema que se basa en la protesta y la acción colectiva para 
mover los marcos de interacción predominantes. Busca el cambio en las reglas del juego, a partir de la premisa que no es posible tener controles eficientes en el gobierno. Por ende, la presión social conllevaría mejores resultados. Esta forma de participación se manifiesta en contra de todo el sistema político, sus relaciones con el sistema económico e incluso asume la irrupción como la única vía de cambio social. La primera década del siglo XXI, es conocida por los movimientos altermundistas y los foros sociales mundiales que brindaron un carácter trasnacional a la protesta (Tamayo 2016: 26, Della Porta y Tarrow 2005).

La protesta, vía movimientos sociales, busca el reconocimiento de derechos. El voto efectivo, el acceso a servicios de salud, mayor cobertura de educación, equidad de género, entre otros derechos reconocidos por el Estado, no se comprende su relato y reconocimiento sin la lucha social. La represión estatal obedeció en su momento a la idea equivocada de que tales movimientos ponían en riesgo la supervivencia del Estado. La protesta ciudadana parte de la premisa que todo avance está simulado o es insuficiente. No se acepta en los movimientos sociales que existen conquistas reconocidas por liderazgos de la contraparte gubernamental, puesto que su razón de ser es la insatisfacción del estado actual de resultados o desempeño ineficaz del Estado. Incluso expresan rechazo a la incidencia que viene de otras formas de participación ciudadana.

El Estado requiere de la participación ciudadana para construir una visión ciudadana del propio Estado. Una ciudadanía basada en el ejercicio de derechos exige garantías mínimas del cumplimento formal y material para alcanzar mejores condiciones de vida. El Estado de ciudadanía tiene como eje central la libre expresión y el derecho a la sociedad de la información, el acceso a la educación y la información como condición indispensable para ejercer derechos sociales y políticos (Pinto y Flisfisch 2011: 93). Sus objetivos centrales son:

a) universalizar los derechos civiles: seguridad ciudadana para todos, recuperando la seguridad; b) universalizar la ciudadanía social, es decir, universalizar el bienestar, tanto en su faz utilitaria como en cuanto dignidad humana (por medio del desarrollo de la ciudadanía social); y c) universalizar el acceso al poder que radica en el Estado, sea por la vía de la representación, sea por formas complementarias de democracia directa, lo cual implica reconstruir la política (Pinto y Flisfisch 2011: 16).

Un Estado de ciudadanía tal como se plantea líneas arriba, sugiere una visión socialdemócrata de la política, basada en la universalización 
de los derechos y políticas, en lugar de la focalización de los derechos y las políticas. No obstante, los movimientos sociales han luchado históricamente por el reconocimiento de la igualdad, aun de aquellos que son reconocidos como diferentes. Un Estado basado en derechos, implica erradicar las fallas en las instituciones públicas, derivadas de sus débiles controles y el ingreso al servicio civil de algunos funcionarios sin formación ética, que solo buscan capturar rentas del Estado, lo que sugiere elevados riesgos de corrupción. La desconfianza que prevalece de manera reciproca entre gobierno y ciudadanos, reduce la posibilidad de lograr una sólida y sostenida participación ciudadana. Más aún, cuando las demandas ciudadanas ratifican o aumentan el conflicto con el gobierno, sin mecanismos que lo reduzcan.

Los modelos de democracia en los cuales se contextualiza la participación ciudadana, importan. Mientras que en la búsqueda del control de los políticos desde el ejercicio de la ciudadanía, la desconfianza, desafección y conflicto, no son los únicos inhibidores de la participación ciudadana. Se suman la impunidad, entendida como la falta de sanciones a quienes incumplen el mandato de administrar los recursos públicos y la indiferencia, resultado de la crisis de valores que viven nuestras sociedades latinoamericanas. La indiferencia implica ausencia de solidaridad y la normalidad de violencia y corrupción entre los ciudadanos. 
Tabla 1: Atributos de la participación ciudadana por categorías

Categoría de análisis

Atributos contrastados

\begin{tabular}{|c|c|c|}
\hline & Democracia participativa & Democracia colaborativa \\
\hline Lógica relacional & Conflicto- colaboración & Colaboración- irrupción \\
\hline $\begin{array}{l}\text { De acuerdo al tipo de } \\
\text { grupo }\end{array}$ & Participación masiva & Élites o grupos participativos \\
\hline $\begin{array}{l}\text { Restricción formal o } \\
\text { informal }\end{array}$ & No institucionalizada & Institucionalizada \\
\hline Respecto al gobierno & Extra-gubernamental & Para-gubernamental \\
\hline $\begin{array}{l}\text { En función del } \\
\text { resultado obtenido }\end{array}$ & No vinculante & Vinculante \\
\hline $\begin{array}{l}\text { De acuerdo a la } \\
\text { preferencia }\end{array}$ & Movimientos sociales & Asociaciones civiles \\
\hline Lógica de desempeño & Control social & Confianza social \\
\hline $\begin{array}{l}\text { Según la demanda } \\
\text { impulsada }\end{array}$ & Reconocimiento de derechos & $\begin{array}{l}\text { Mejorar acceso a servicios y } \\
\text { ejercicio de derechos }\end{array}$ \\
\hline $\begin{array}{l}\text { En atención a los } \\
\text { grupos }\end{array}$ & Redes sociales digitales & $\begin{array}{c}\text { Redes de coaliciones o } \\
\text { colectivos }\end{array}$ \\
\hline De acuerdo al número & Individual- agregativa & Colectiva- deliberativa \\
\hline Según su naturaleza & Anti sistémica (protesta) & Sistémica (propuesta) \\
\hline $\begin{array}{c}\text { De acuerdo al contexto } \\
\text { estatal }\end{array}$ & Estado gobierno & Estado de ciudadanía \\
\hline Según el asunto público & De denuncia & De prevención \\
\hline
\end{tabular}

Fuente: Elaboración propia.

\section{IMPLICACIONES DE LA PARTICIPACIÓN CIUDADANA EN EL COMBATE A LA CORRUPCIÓN}

La corrupción se explica, en parte, por la falta de contrapesos ciudadanos que vigilen el uso de recursos fiscales y los presupuestos, así como por la inactividad del mecanismo de pesos y contrapesos que supone el equilibrio de poderes. Los últimos cuarenta años se asumió en México que la corrupción era un tema exclusivo del sector gubernamental. Esto ha cambiado, al menos en las leyes. La corrupción también se genera desde la sociedad civil, no solo desde el gobierno. Existe cierta normalización de la corrupción como forma de vida para escalar social y económicamente, lo que sugiere la inexistencia de ambientes de integridad y ética pública, además que por mucho tiempo su manifestación era socialmente castigada. En México, se afirmaba que político pobre (términos que alude a una reducida posesión de bienes materiales), era un pobre político (sin éxito ni reconocimiento). 
El cambio de valores basados en la democracia y la transparencia promovidos desde, y en la esfera social, motivó el aumento de capacidades y saberes ciudadanos contra la corrupción. Pero la relación con el Estado sigue siendo asimétrica y desigual. La concentración de la riqueza sugiere que el poder económico prefiere mantener el statu quo del sistema político. El consenso del cual nace todo sistema, política pública, plan o estrategia de combate a la corrupción, debe reconocer que la corrupción dejó de ser un asunto funcional para el desarrollo democrático de nuestras sociedades.

Así como las reformas político-electorales que consolidaron la democracia en su versión procedimental, surgieron de consensos motivados por la presión que impactó en la esfera de la política de igual forma se generaron reformas que crearon nuevos diseńos y mecanismos y políticas anticorrupción. Los efectos que tuvieron las crisis política, económica y social en la década de los noventas, devino una espiral de reformas al poder que terminó por establecer nuevas reglas en la función reguladora del Estado sobre el mercado.

Bajo la idea de combatir el autoritarismo encarnado en la figura de los presidentes latinoamericanos, la participación de ciudadanos no tuvo inicialmente importante eco en las reformas políticas. Al mismo tiempo el Estado vio mermada su capacidad para resolver problemas ańejos de la agenda. Esto derivó en una concentración del poder económico, y el paulatino crecimiento de las OSCs. Su involucramiento en el espacio de lo público fue consistente con sumar y multiplicar capacidades institucionales. La acción pública, hoy en día, requiere corresponsabilidad entre gobierno, empresa y sociedad, ante los reclamos de mejores servicios públicos y ambientes libres de corrupción.

Existe una trayectoria histórica de la corrupción, pero también un esquema de incentivos y pagos que sugiere a ciertos grupos políticos y élites económicas, accionar sus herramientas para mantener el estado actual de cosas. Mientras la corrupción fue normalizada, el cambio de valores en la sociedad la convirtió en causa y efecto de graves problemas públicos. De este modo, se ha probado que en el sector salud la corrupción mata a los pacientes debido a la escasez de medicinas; frente a desastres naturales, la corrupción mata a ciudadanos cuando se derrumban edificios que caen por mala calidad de la construcción; la corrupción mata a jóvenes, cuando ocurren tragedias en negocios de diversión que obtuvieron permisos mediante sobornos.

Con base en el contexto anteriormente descrito, la revisión del marco legal y exploración de la actividad que desarrollan los comités de participación 
ciudadana (CPC) de los sistemas anticorrupción de México, se perfilan algunas hipótesis para comprender el fenómeno de la corrupción. La primera hipótesis (H1) indica que la participación ciudadana sí tiene implicaciones en el combate a la corrupción. Según sean los atributos activados en los procesos de participación (véase Tabla 1), será el grado de la implicación ciudadana. El resultado de la intervención ciudadana dependerá de una combinación de factores contextuales, organizacionales e institucionales. ¿Cuáles son las implicaciones a las que alude la $\mathrm{H} 1$ en el combate a la corrupción? Algunas implicaciones positivas son las siguientes:

Implicación 1. De contrapeso extra e intragubernamental. La función de contrapeso ciudadano mediante acciones de vigilancia, monitoreo y evaluación de la acción gubernamental, son algunos ejemplos de intervención que inciden e influyen en reformas políticas y administrativas, diseño de políticas y estrategias, alertas de ciudadanos o denuncias públicas que pudieran iniciar investigaciones.

Implicación 2. De aumento en la calidad del gobierno. La participación ciudadana es esencial en el proceso de mejorar la calidad institucional de los gobiernos y sentar bases para un nuevo servicio público, mediante un mecanismo de escucha activa de la administración pública, que incorpore la inteligencia colectiva a gran parte de las soluciones que instrumenta el gobierno para mejorar su desempeño.

Implicación 3. De cambio cultural inclusivo. Es importante incorporar a la participación ciudadana a los actores que aún están excluidos. Una función esencial de la participación es otorgar voz a los ciudadanos que no la tienen, mediante la creación de oportunidades de desarrollo en contextos de ética e integridad y no en contextos contaminados de influyentismo.

Estas tres implicaciones sugieren que la participación ciudadana debe reconceptualizarse en dos ámbitos relacionales, uno de ciudadanos con el gobierno y el otro de ciudadanos con otros ciudadanos. Las relaciones no se representan únicamente en forma bidireccional, sino en múltiples sentidos y en múltiples grupos de ciudadanos, diversos y de pensamiento plural.

La participación que deriva de la $\mathrm{H} 1$, tiene tres implicaciones positivas descritas líneas arriba, pero también tiene implicaciones negativas, como las anotadas enseguida.

Implicación 4. El riesgo del monopolio de la participación. Los ciudadanos, en ocasiones, producen condiciones que favorecen el monopolio de la participación en detrimento de los incentivos que pudieran tener otros ciudadanos para intentar incidir en el mismo issue. 
El monopolio es ocasionado por la captura de los espacios institucionales y no institucionales de participación. Incluso, cuando se detenta el monopolio de la participación, este grupo de ciudadanos intenta destruir toda posibilidad de construir una base más amplia participativa.

Implicación 5. Del alcance de la participación. Los aspectos de la gestión pública que se solicita modificar a petición de ciudadanos, sin analizar el origen y consecuencias del cambio, producen en ocasiones barreras que obstaculizan el servicio público y terminan por aumentar las zonas de corrupción, en lugar de reducirlas. Es un efecto contrario al deseado.

Implicación 6. De las consecuencias de soluciones simples. Ciertos problemas como el combate a la corrupción no admiten soluciones simples, ni resultados de corto plazo que sean duraderos. Si no se asume la complejidad y la discusión pública de los temas, sino se reconoce la complejidad y el alcance de la participación, se pone a prueba el nivel de frustración y la motivación de la participación de ciudadanos.

Cada una de estas seis implicaciones, positivas y negativas, constituye líneas de pensamiento de las cuales es factible articular y perfilar futuras líneas de trabajo que contribuyan a generar conocimiento aplicado que facilite conocer, describir o explicar, la relación que guarda la participación ciudadana con la administración pública, especialmente en el combate a la corrupción.

Una segunda hipótesis de trabajo (H2) apunta que las fórmulas para el combate a la corrupción, son de alcance limitado por sí solos, requiere de la combinación de distintas fórmulas con ingredientes predictivos, de control, de prevención, de monitoreo y de sanción de actos o hechos de corrupción, que reflejen como resultado una mayor coordinación entre autoridades y ciudadanos que participan activamente en el combate a la corrupción.

Bajo diversos contextos de impunidad que prevalecen en México y las bajas probabilidades de sancionar actos de corrupción por ausencia de una cultura de denuncia y legalidad, la suma de algunos antídotos es pieza fundamental en el diagnóstico y planes estratégicos para mitigar este mal endémico.

Antídoto 1. Gobierno abierto para mejorar la calidad de la decisión. La clave de la apertura gubernamental está cimbrada en la participación ciudadana que utiliza la información generada por el gobierno y se involucra con cierto grado de conocimiento en la gestión de soluciones 
a los problemas colectivos, especialmente aquellos que son críticos y urgentes. El gobierno no puede enfrentar los problemas de corrupción en solitario. Requiere sumar a sus procesos decisorios capacidades ciudadanas e inteligencia colectiva que favorezca el trabajo coordinado, sistematizado y en red. Los gobiernos abiertos implican procesos en red, y la red a su vez un sistema que aspira primero a coordinarse, equilibrarse y posteriormente trazar agendas autónomas con objetivos compartidos.

Antídoto 2. Big data, small data y gobierno digital para mejorar prestación de servicios públicos. Se propone la relación de herramientas y plataformas digitales que recopilen datos en grandes cantidades para identificar y simplificar trámites para el ciudadano, reduciendo zonas de corrupción y generando certidumbre en los procedimientos a ciudadanos. El gobierno digital es fundamental para la relación entre empresas con gobierno, especialmente en el momento de la contratación y asignación de servicios, definición de proveedores y contratos de obras de infraestructura. La eliminación del soborno, será posible si se introduce el concepto de ética pública en los procesos de contratación, si se solicitan certificaciones a los procedimientos de las empresas para establecer justa competencia en licitaciones y generar el mecanismo de apertura a estos procesos para el seguimiento ciudadano. Facilitar puntos de contacto entre empresas y gobierno a través de plataformas, ayuda sobre manera a reducir la interacción que corrompe el resultado del proceso contratación de obras.

Antídoto 3. Rendición de cuentas sociogubernamental, intergubernamental y corporativa. Abrir la puerta de las administraciones públicas a ciudadanos para verificar, opinar, revisar, monitorear y evaluar, tendrá beneficios en el mediano y largo plazo. Conducido con método y legitimidad, en el corto plazo facilitará al Mandatario del gobierno en turno, controlar a su estamento directivo y mantener finanzas blindadas contra la corrupción. Sumado a los controles de fiscalización existentes entre los poderes, los controles ciudadanos e institucionales, se multiplicaría el efecto de rendición de buenas cuentas, y hace de ellos una fórmula poderosa con alta probabilidad de éxito en el combate a la corrupción.

En suma, el combate a la corrupción quedará contenida, y reducida progresivamente, mediante un aumento en la calidad de la decisión pública, más rendición de cuentas hacia la sociedad y uso de la información para elevar la calidad de los servicios públicos. 


\section{DESTELLOS DE LA EXPERIENCIA DEL SISTEMA ANTICORRUPCIÓN EN MÉXICO}

En México el SNA es resultado de una transformación del federalismo mexicano de competencias, hacia un federalismo cooperativo basado en la coordinación para lograr mejores resultados. Con la creación de sistemas nacionales, la coordinación y las facultades concurrentes son la característica central, y con ello se pretende tener mejor calidad de respuesta institucional ante los problemas de corrupción en México. Con la creación de un Sistema Nacional, ahora está en manos de los tres órdenes de gobierno las acciones de combate de la corrupción y también las acciones anticorrupción. Entenderemos por combate a la corrupción, las sanciones y castigos, mientras que acciones anticorrupción, la prevención y el fomento a la integridad pública.

En México, las primeras acciones en contra de la corrupción datan desde 1982, con la creación de la Secretaría de la Contraloría General de la República, oficina del gobierno federal responsable de la sanción administrativa y el control interno. Una crisis política, económica y fiscal, antecede a la creación de los órganos de control interno del gobierno federal, que tienen como propósito verificar el gasto del gobierno, teniendo como resultado la sanción e inhabilitación para desempeñar cargos públicos.

A pesar de esta reforma político- administrativa de 1982, en México la corrupción se normalizó, pensando que solo era un asunto del sector gubernamental. Fue con las reformas políticas de 2015 que se reconoció el carácter multicausal de la corrupción, es decir, como una amplia red de problemas. La creación del SNA como vía de combate sistémico, coordinado y ciudadanizado, es el diseño institucional que se puso en marcha en México. La idea de un sistema, es combinar las distintas funciones del Estado, en el combate a la corrupción: la fiscalización de recursos públicos, el control interno de la administración pública, la sanción administrativa y penal, la transparencia y el acceso a la información pública, la incorporación de jueces y magistrados, así como la participación ciudadana institucionalizada.

De esta forma, la lucha anticorrupción implicará no solo el castigo, sino la prevención y la socialización de la integridad y ética públicas. Actualmente el SNA tiene en marcha la aprobación de una propuesta de Política Nacional Anticorrupción, resultado del trabajo de la Secretaría Ejecutiva, órgano operador y técnico responsable de articular todo el SNA, en consulta con la sociedad civil. 
El SNA se forma con dos Comités: El Comité Coordinador y el Comité de Participación Ciudadana (CPC). El Presidente del segundo, preside el primero por disposición de la Ley.

El Comité Coordinador agrupa a los entes gubernamentales, mientras que el CPC a cinco ciudadanos seleccionados por sus méritos y trayectoria en el ámbito de la transparencia y la rendición de cuentas, cuya función principal es la vinculación con la sociedad civil. El Comité Coordinador está formado por siete titulares de organismos que combaten la corrupción: 1) Auditor Superior de la Federación; 2) Magistrado Presidente del Tribunal de Justicia Administrativa; 3) Comisionado Presidente del Instituto de Transparencia, Acceso a la Información Pública y Protección de Datos Personales; 4) Representante del Consejo de la Judicatura Federal del Poder Judicial de la federación; 5) Fiscal Anticorrupción de la República; y 6) la Secretaria de la Función Pública del Gobierno de la República, sumando seis integrantes gubernamentales; y lo preside 7) un representante del CPC.

El Comité Coordinador se define como "la instancia responsable de establecer mecanismos de coordinación entre los integrantes del Sistema Nacional y tendrá bajo su encargo el diseño, promoción y evaluación de políticas públicas de combate a la corrupción" (Ley General, 2015: 4). Aquí deliberan representantes del poder ejecutivo, del poder judicial y organismos autónomos. El Comité Coordinador tienes dos funciones sustantivas en el SNA, emitir recomendaciones no vinculantes y aprobar para su implementación, la Política Nacional Anticorrupción. Aun cuando pertenecen al Comité Coordinador instancia, instituciones que imponen sanciones, como el caso de la Fiscalía Anticorrupción y la Auditoria Superior de la Federación, entre otros, en su conjunto el Comité Coordinador como colegiado puede emitir recomendaciones a otros entes ajenos al SNA para prevenir, mejorar o tomar medidas anticorrupción.

Un sistema adquiere vida no por la suma de sus partes sino por las conexiones e intercambios que logre acreditar, a nivel de conjunto, decisiones compartidas en temas específicos. No basta la suma de sus partes, exige un funcionamiento comunicado e interdependiente. Es por ello que no se trata de un sistema autónomo, sino de un sistema coordinado que toma acuerdos y decide acciones que resuelvan asuntos de corrupción con integralidad.

El poder ciudadano del SNA está depositado en el CPC, un colegiado que agrupa a cinco ciudadanos designados por una Comisión nombrada por el Senado de la República para seleccionar a quienes formarán el CPC. Ésta última es la instancia responsable de vincular al SNA con la sociedad civil y la academia, además de presidir todo el sistema. Lo anterior implica 
que el SNA tiene la virtud de ser presidido por un ciudadano que no forma parte el gobierno, sino por un ente público ciudadanizado como es el CPC. Es el único sistema de todos los que existen en México con esa característica.

\section{EL ANTECEDENTE DEL SNA}

El CPC es más un monitor, un vigilante y promotor de los valores del SNA, que un contrapeso del Comité Coordinador. El diseño institucional prevé que el Presidente del CPC se integra al Comité Coordinador y lo preside y el resto de los cinco integrantes del CPC, es decir, cuatro, se suman a una Comisión Ejecutiva que es convocada por el titular de la Secretaría Ejecutiva.

La fortaleza del CPC no está dentro del SNA, sino fuera del mismo. $\mathrm{Al}$ ser responsable de vinculación con sociedad civil y academia, su poder de gobernanza se encuentra en las conexiones al exterior del SNA y la socialización de las decisiones que ha tomado el Comité Coordinador, los planes y proyectos en marcha.

Los CPC se crean en la Ley General del SNA, y para comprender su función, es clave conocer el antecedente inmediato del cual derivó su creación. Tres hechos marcan el antecedente del nacimiento del SNA en México:

1. La iniciativa de reforma del Partido Revolucionario Institucional (PRI) en 2013, a la Ley Orgánica del Poder Ejecutivo para extinguir la Secretaría de la Función Pública (SFP) y transferir sus atribuciones a la Secretaria de Hacienda y Crédito Público (SHCP) ${ }^{2}$. Una reforma que se aprobó, pero no entró en vigor el transitorio que desparecería la SFP, Dependencia o Ministerio responsable del control interno de la administración pública. Supervisa que el gasto sea responsable, transparente y acorde a los principios de economía, eficacia y eficiencia. Su desaparición, hubiera implicado la inexistencia de contrapesos al interior de la administración pública federal. La entidad responsable del ejercicio presupuestal, es decir, la SHCP, se supervisaría así misma. Finalmente se mantiene la SFP y se creó el SNA, al cual pertenece el responsable del control interno.

2 Véase iniciativa de reforma de diversas disposiciones de la Ley Orgánica de la Administración Pública Federal, del 2 de enero de 2013. Página web de la Cámara de Diputados del Congreso de la Unión. http://www.diputados.gob.mx/sedia/biblio/ prog_leg/015_DOF_02ene13.pdf 
2. El movimiento 3 de 3 (www.3de3.mx) que generó en 2014 la iniciativa ciudadana de Ley General del Sistema Nacional Anticorrupción, motivados por la existencia de casos de corrupción que se identificaron en el sexenio del Presidente de México Enrique Peña Nieto. La existencia del movimiento 3 de 3 , fue resultado de las organizaciones de la sociedad civil que liderean el monitoreo de la actividad gubernamental. A partir de los contratos otorgado por el gobierno federal a favor del grupo HIGA y de Odebrecht, se conoció de la existencia de conflicto de interés en la licitación de obra pública. El primer contrato a favor de grupo HIGA, se identificó que la familia del Presidente de la República y que el Titular de la SHCP habían celebrado contratos de compra venta de inmuebles de valor millonario con filiales del grupo HIGA, empresa que recibió contrato de obra pública para el tren rápido QuerétaroCiudad de México. Fue el propio Presidente quien ordenó una investigación al Titular de la SFP para determinar si existió conflicto de interés derivado de las operaciones realizadas sobre los bienes inmuebles. Como resultado de la investigación y substanciación del caso que realizó la SFP, las denuncias fueran archivadas y terminaron por exonerar a los involucrados en el episodio de la política mexicana conocido como Casa Blanca. Así la sociedad civil puso especial atención en exigir la publicidad de las declaraciones patrimoniales y exigió sea obligatorio declarar el conflicto de interés. Otro acontecimiento que produjo fuertes presiones al Estado Mexicano del movimiento 3 de 3 fue por la contratación de obra pública de Petróleos Mexicanos con la empresa multinacional brasileńa Odebrecht. Como anota Montes (2019), Odebrecht sobornó a políticos mediante el financiamiento ilegal de campañas electorales para obtener contratos millonarios en Brasil, y se dio a conocer que su operación de extendió de forma similar en México, Colombia y Perú. Del caso mexicano, se generó carpeta de investigación en la Fiscalía Especializada en delitos Electorales de la Fiscalía General de la República. El movimiento 3 de 3 promovido por Transparencia Mexicana y el Instituto Mexicano para la Competitividad (IMCO) y diversas organizaciones aliadas de empresarios, académicos y líderes sociales, determinó convertir el movimiento en una iniciativa que buscó la publicidad de tres tipos de declaraciones: patrimonial, de interés y fiscal. La primera se realiza anualmente por los servidores públicos, pero no existía versión pública. Las otras dos, se realizan voluntariamente a partir de un registro en plataforma creada por el IMCO, donde se puede consultar quienes realizaron su 3 de 3.

3. La ratificación de la membresía de México en la Alianza Global de 
Gobierno Abierto (AGA) y la asunción a la Presidencia de la AGA en 2015, facilitó realizar prácticas de gobierno y parlamento abierto, con el aval y guía del Instituto Nacional de Transparencia Acceso a la Información Pública y Protección de Datos Personales (INAI) y organizaciones de la sociedad civil.

La iniciativa 3 de 3 logró recibir las firmas suficientes para introducir al Congreso de la Unión, la iniciativa ciudadana de creación del SNA y la obligatoriedad de presentar a servidores públicos la declaración patrimonial en formatos públicos, declaración de conflicto de interés y declaración fiscal. Este resultado fortaleció el ambiente propicio para llevar adelante una gran reforma política y administrativa anticorrupción, siendo los ciudadanos organizados quienes presentaron la iniciativa de reforma constitucional.

Mediante una práctica de Parlamento Abierto, se discutió entre congresistas y ciudadanos promotores de la iniciativa, el diseño de toda la estructura institucional que haría frente a la lucha anticorrupción. La mesa de trabajo concluyó en mayo de 2015 con la reforma constitucional publicada en el Diario Oficial de la Federación, que consideró diversas disposiciones de la Constitución Política de $\mathrm{México}^{3}$, destacando la creación del SNA en el artículo 113 constitucional y la ampliación de la base de responsabilidades administrativas para incluir sanciones, no solo a servidores públicos, sino también a particulares que ofrezcan sobornos al gobierno para obtener contratos y hacer equiparable a los servidores públicos la actuación de particulares con el gobierno.

Desde la Constitución se mandató la creación de un nuevo marco legal que prevea la aplicación de sanciones a servidores públicos y ciudadanos que cometan hechos de corrupción. Anteriormente solo se sancionaba al servidor público, hoy en día se sanciona también al particular que, en relación con el gobierno, obtiene beneficios ilegales. Tales sanciones son de carácter penal, mediante denuncia ante Fiscalía Especializada en Delitos sobre Hechos de Corrupción y sanciones administrativas mediante denuncia ante la SFP. La aplicación de sanciones económicas y privativas de libertad, hizo necesario que forme parte del SNA un representante del Poder Judicial de la Federación.

En 2016 se expidieron las normas jurídicas de responsabilidad administrativa y en materia penal sobre hechos de corrupción, que dieron contenido operativo a la reforma constitucional de 2015, bajo un marco

3 Formalmente es Constitución Política de los Estados Unidos Mexicanos. 
de distribución de competencias que definió gran parte de la operación de todo el SNA y de cada uno de sus integrantes. La Ley General del SNA establece que el sistema es "una instancia cuya finalidad es establecer, articular y evaluar la política en la materia" (Ley General 2015: 3). Es decir, es la suma de instancias que en su mayoría ya existían con propósito de coordinación. No es una nueva estructura orgánica, sino un "mecanismo que coordina distintas autoridades de los tres órdenes de gobierno que tienen la responsabilidad de promover la rendición de cuentas y el combate a la corrupción en el quehacer público" (Ethos 2017: 9).

\section{EL PODER DE CIUDADANOS EN LA GOBERNANZA DEL SNA}

El SNA tiene como objetivo principal "la prevención, investigación y sanción de las faltas administrativas y hechos de corrupción al igual que el fortalecimiento institucional de las instancias que lo componen" (Ethos 2017: 25).

Los ciudadanos designados para constituir el CPC cumplen una función pública, pero no son servidores públicos en sentido estricto. La Ley General reservó para los ciudadanos: prevención en forma de monitoreo, vinculación y acompañamiento a la sociedad civil y academia, así como el fomento de la denuncia. Además, emite exhortos al Comité Coordinador y a los entes de gobierno para cumplir con acciones anticorrupción. El CPC destaca por tratarse de un conjunto de ciudadanos que deciden participar en la vida pública mediante una participación ciudadana institucionalizada, para promover acciones de impacto social y político.

El Presidente del CPC funge como Presidente del Comité Coordinador y Presidente del Órgano de Gobierno de la Secretaria Ejecutiva, ésta última es la entidad pública descentralizada, no sectorizada en la administración pública, con personalidad jurídica que recibe presupuesto público y cuenta con patrimonio propio, con autonomía de gestión presupuestal y fue creada para operar los insumos técnicos del Comité Coordinador. El Presidente del CPC es, por tanto, el Presidente de todo el sistema.

La misma estructura del SNA, se reproduce en 32 entidades federativas de México. Los sistemas estatales anticorrupción (SEA) están constituidos en todo el territorio nacional mexicano, excepto en Chiapas, entidad federativa que cuenta con la normatividad y está en proceso de selección de sus integrantes. Prácticamente todos los SEA, replican la estructura del SNA en cuanto a la creación de los dos Comités: 1) CPC y 2) Comité Coordinador. 
Al igual que sucede en el SNA, en los SEA existe un Secretario Ejecutivo como Organismo Público Descentralizado, no sectorizado con alguna Secretaría o Ministerio del Estado mexicano. La composición de cinco integrantes de cada CPC por entidad federativa se replica a lo largo del país, excepto en el caso de Baja California. En todos los casos el Presidente del CPC preside el SEA y el resto de los integrantes forman parte de la Comisión Ejecutiva, instancia que encabeza el Secretario Ejecutivo para generar insumos técnicos para el Comité Coordinador ${ }^{4}$. A partir de la revisión a las leyes estatales que crean los Sistemas Anticorrupción, se pudo identificar algunas características en cuanto a su composición, lo que sugiere que los SEA tienen algunas variantes en interacción CPC y Comité Coordinador (Ver tabla 2).

Tabla 2: Los Comités de Participación Ciudadana en los Sistemas Estatales Anticorrupción

\begin{tabular}{ccc} 
Entidad federativa & $\begin{array}{c}\text { Número de } \\
\text { integrantes } \\
\text { CPC }\end{array}$ & $\begin{array}{c}\text { Relación con el Comité } \\
\text { Coordinador (CC) }\end{array}$ \\
\hline Aguascalientes & 5 & 1 integrante del CPC preside el CC \\
Baja California & 15 & 11 integrantes del CPC forman \\
parte del CC y 1 lo preside \\
Baja California Sur & 5 & 1 integrante del CPC preside el CC \\
Campeche & 5 & 1 integrante del CPC preside el CC \\
Chiapas & 5 & 1 integrante del CPC preside el CC \\
Chihuahua & 5 & 1 integrante del CPC preside el CC \\
Coahuila de Zaragoza & 5 & 1 integrante del CPC preside el CC \\
Colima & 5 & 1 integrante del CPC preside el CC \\
Ciudad de México & 5 & 1 integrante del CPC preside el CC \\
Durango & 5 & 1 integrante del CPC preside el CC \\
Guanajuato & 5 & 2 integrantes del CPC forman parte \\
Guerrero & 5 & 1 integrante del CPC preside el CC \\
Hidalgo & 5 integrante del CPC preside el CC
\end{tabular}

4 Al titular de la Secretaria Ejecutivo, se le denomina Secretario Técnico, pero se le denominará para efecto de este articulo Secretario Ejecutivo. 


\begin{tabular}{|c|c|c|}
\hline Entidad federativa & $\begin{array}{l}\text { Número de } \\
\text { integrantes } \\
\text { CPC }\end{array}$ & $\begin{array}{l}\text { Relación con el Comité } \\
\text { Coordinador (CC) }\end{array}$ \\
\hline Jalisco & 5 & 1 integrante del CPC preside el CC \\
\hline Estado de México & 5 & 1 integrante del CPC preside el CC \\
\hline Michoacán de Ocampo & 5 & 1 integrante del CPC preside el CC \\
\hline Morelos & 5 & 1 integrante del CPC preside el CO \\
\hline Nayarit & 5 & 1 integrante del CPC preside el CC \\
\hline Nuevo León & 5 & $\begin{array}{l}3 \text { integrantes del CPC forman parte } \\
\text { del CC y } 1 \text { lo preside }\end{array}$ \\
\hline Oaxaca & 5 & 1 integrante del CPC preside el CC \\
\hline Puebla & 5 & 1 integrante del CPC preside el CC \\
\hline Querétaro & 5 & 1 integrante del CPC preside el CC \\
\hline Quintana Roo & 5 & 1 integrante del CPC preside el CC \\
\hline San Luis Potosí & 5 & 1 integrante del CPC preside el CC \\
\hline Sinaloa & 5 & 1 integrante del CPC preside el CC \\
\hline Sonora & 5 & 1 integrante del CPC preside el CO \\
\hline Tabasco & 5 & 1 integrante del CPC preside el CC \\
\hline Tamaulipas & 5 & 1 integrante del CPC preside el CC \\
\hline Tlaxcala & 5 & 1 integrante del CPC preside el CC \\
\hline Veracruz de Ignacio de la Llave & 5 & 1 integrante del CPC preside el CC \\
\hline Yucatán & 5 & 1 integrante del CPC preside el CC \\
\hline Zacatecas & 5 & 1 integrante del CPC preside el CC \\
\hline Totales & 170 & $\begin{array}{c}45 \text { integrantes del CPC como parte } \\
\text { del CC }\end{array}$ \\
\hline
\end{tabular}

Fuente: Elaboración propia mediante consulta de la legislación de la materia.

En el proceso de la hechura de la decisión del SNA y del SEA, la relación entre el CPC y el Comité Coordinador es asimétrica. De la Tabla 2 se desprende que los CPC locales siguen la estructura nacional de siete integrantes y solo uno es integrante del CPC, y es quien preside el Comité Coordinador. Pero existen tres casos de excepción. Son los casos de Baja California, Guanajuato y Nuevo León. Estos casos muestran mayor 
proporción de incidencia al interior del Comité Coordinador.

La proporción de incidencia ciudadana en el Comité Coordinador se define como la probabilidad de que ciudadanos participen influyendo en la toma de decisiones del SNA, o SEA. Para su cálculo, se contabiliza el número de integrantes del $\mathrm{CPC}$ en el Comité Coordinador, y se divide sobre el total de integrantes de los CPC en el territorio nacional ${ }^{5}$. El resultado indica que el 26,4\% de los ciudadanos que integran los CPC de las entidades federativas tiene la probabilidad de incidir en las decisiones más relevantes del SEA. La proporción de incidencia es baja.

Aunque en la Comisión Ejecutiva se forma por cuatro de los integrantes del CPC, las decisiones ahí tomadas se llevan al Comité Coordinador para su aprobación final. La Comisión Ejecutiva es formada por integrantes del CPC excepto su presidente, y existe para promover acuerdos con el Secretario Ejecutivo y proveer insumos técnicos necesarios para el proceso de toma de decisiones del Comité Coordinador.

De ahí la relevancia de los perfiles seleccionados para el CPC, estén sustentados en la profesionalización, competencias probadas y trayectoria en el tema, debido a que su función no solo es la vinculación con la sociedad civil y academia, sino que realizan una actividad técnica, política y social anticorrupción.

Los integrantes del Comité Coordinador realizan funciones preventivas, de investigación, de control, sanción, fiscalización, de monitoreo, de profesionalización y de transparencia, es decir, no son un ente monolítico, sino que representa la correlación de distintas funciones, cada uno en tanto es un engrane del sistema.

Cabe precisar que, aunque la participación ciudadana está institucionalizada en el combate a la corrupción a través del CPC, pero no se trata de un solo bloque ciudadano uniforme, sino de un cuerpo colegiado plural y diverso, con perspectivas diferenciadas acerca de lo que implica la ciudadanización del sistema, y será fundamental conciliar miradas en su relación con la parte de gobierno, y su forma de alcanzar la vinculación con la academia y la sociedad civil.

5 La ecuación se representa de la siguiente forma: PICC $=\sum(\mathrm{x}) / \sum(\mathrm{y})$; donde PICC es igual a proporción de incidencia en el Comité Coordinador, igual a la suma de integrantes de CPC dentro del CC en todo México, entre la suma del total de integrantes de CPC en todo el país, por cien por ciento. $\mathrm{PICC}=45 / 170^{*} 100=26.4 \%$. 


\section{CONCLUSIONES}

La investigación condensa algunas corrientes teóricas de la participación ciudadana y aborda una reflexión de la composición del Sistema Anticorrupción en México, nacional y estatales, para construir una mirada que describa sus principales características. Los CPC son la vía institucionalizada que el SNA dispone para generar la confianza que permita al ciudadano apropiarse de herramientas para la creación de nuevas redes ciudadanas contra la corrupción.

Por tanto, la participación ciudadana es una poderosa herramienta para generar consensos y procesar los disensos con base en la regla de la mayoría. Este sistema indica la importancia de la corresponsabilidad en la construcción de las decisiones públicas, especialmente en democracias en vías de consolidación donde existe una cultura de ilegalidad y desconfianza. La participación ciudadana si tiene implicaciones en el combate a la corrupción, aunque en sí misma es insuficiente si no se acompañe de otros ingredientes que fortalezcan la gestión de la participación ciudadana en el SNA.

La H1 indicó que la participación ciudadana sí tiene implicaciones en el combate a la corrupción, pero resta probar mediante modelización, si las seis implicaciones prevalecen las positivas o las negativas en los márgenes de actuación de todo el SNA.

Los CPC, al fortalecer su capacidad de incidir en las organizaciones de la sociedad civil será posible canalizar un cambio en los hábitos cotidianos donde el cumplimiento de la ley es la ausente. La lucha anticorrupción de manera sistémica es la oportunidad de crear valor social, mediante una estrecha alianza entre los CPC y las organizaciones de la sociedad civil, relación que pueda llegar al empoderamiento y apropiación de las herramientas en el combate a la corrupción, como es el gobierno abierto y la transparencia total del gobierno.

Las elevadas expectativas que los ciudadanos, se disuelven cuando se conoce que la lucha a la corrupción es incremental y no de cambios radicales. Está sujeta a la apertura de ventanas de oportunidad de cambio.

La H2 sostiene que las fórmulas para el combate a la corrupción requieren de la combinación de distintos ingredientes predictivos, reductores de complejidad, de control, de prevención, de monitoreo y de sanción de actos o hechos de corrupción, que reflejen una mayor coordinación entre autoridades y ciudadanos activos en el combate a la corrupción. 
La H2 sugiere que un Sistema Nacional o Estatal será insuficiente si no promueve o crea herramientas como el gobierno abierto, gobierno digital, transparencia proactiva, inteligencia colectiva y administrativa, justicia abierta, políticas públicas deliberativas, rendición de buenas cuentas, entre otras.

La capacidad de sumar y combinar propuestas de solución, será un factor determinante del éxito o fracaso en la lucha contra corrupción. La complejidad para procesar decisiones de forma precisa en la lucha contra la corrupción, conduce a identificar en los cambios de autoridades en el gobierno, la posibilidad de retroceder en avances y logros.

La corrupción es un concepto que permaneció anclado por definición al sector público, pero ahora se reconoce que la red de problemas involucra a ciudadanos y empresas. Bajo esta óptica y consistente con la redistribución del poder en las esferas política, social y económica, se reconoce a nuevos actores en red que, bajo un esquema de corresponsabilidad con el Estado, tienen elevada incidencia a través de la participación en los asuntos públicos.

La ciudadanización del SNA generó un conjunto de relaciones de difícil comprensión y trae consigo cierta dosis de escepticismo en los resultados por alcanzar. A diferencia de otros sistemas nacionales creados en México, el SNA se reproduce con énfasis en la participación de ciudadanos. Los ciudadanos del CPC se constituyen el órgano técnico asesor del Secretario Técnico (Comisión Ejecutiva) y destaca el ejercicio de la Presidencia del SNA. A pesar de lo anterior, aún se requiere transitar de la participación a la incidencia e influencia de tal participación en procesos decisorios. No es suficiente participar.

Los procesos de ciudadanización requieren gestionarse con propósitos de brindar resultados en el mediano y largo plazo. Será posible gestionar exitosamente la participación ciudadana, si se afina el mecanismo de gobernanza en el Comité Coordinador. Desde su origen, el diseño institucional relegó un aspecto central en la gobernanza del SNA, limitando a un solo ciudadano del CPC el llevar la voz de todo el colegiado ciudadanizado al proceso de toma de decisiones. Se requiere a todo el CPC interactuando en el Comité Coordinador. Estas fallas de diseño institucional, limitan la capacidad institucional de actuación del CPC hacia adentro y fuera del SNA.

La importancia de crear y gestionar una agenda propia del SNA, favorece los equilibrios entre los actores participantes en el Comité Coordinador. Retomar las implicaciones positivas de la participación ciudadana descritas 
en este artículo, solo son punto de partida para construir acuerdos que faciliten la superación de fallas en el diseño institucional. Es fundamental abrir el SNA y los SEA a la interacción con otros actores de gobierno, del sector empresarial, de sociedad civil y de academia.

Ciudadanizar los sistemas anticorrupción en México, representa un avance. Ahora se requiere gestionar la participación ciudadana y sus interacciones con el Comité Coordinador, para consolidar la gobernanza de todo el sistema. Para lograrlo es imprescindible consolidar resultados de mediano y largo plazo. No será con acciones aisladas que se desmantela una red de problemas de corrupción. Se requiere de una red sistematizada de alternativas de solución. De ahí la importancia del sistema como mecanismo de coordinación, pero bajo un arreglo institucional que evolucione hacia la gestión de la participación ciudadana como promotor de esas alternativas de solución. 


\section{REFERENCIAS}

Aguilar, L. (2015). Gobierno y administración pública. México: Fondo de Cultura Económica.

Aguirre, J. (2013). Nuevos alcances de la participación ciudadana a través de las redes sociales. Culturales, época II, I (2), 119-150.

Bankole, O. (2015). Anatomy of corruption in the Nigerian public sector: Theoretical perspectives and some empirical explanations, SAGE Open, $1-16$.

Bratu, R. y Kazoka, I. (2018). Metaphors of corruption in the news media coverage of seven European countries. European Journal of Communication, 33 (1), 57-72.

Casar, A. (2016). México: Anatomía de la corrupción. Mexicanos contra la corrupción y la impunidad. México: IMCO.

Comisión Económica para América Latina y el Caribe (CEPAL) (2019). Panorama Social de América Latina, 2018. LC/PUB.2019/3-P. Santiago de Chile: CEPAL.

Della Porta, D. y Tarrow, S. (2005). Transnational protest and global activism. Oxford: Rowman and Littlefi eld Publishers, Inc.

Dye, T. (1972). Policy analysis and political science: Some problems at the interface. Policy Studies Journal, I (2), 103-107.

Ethos (2017). Sistema Nacional Anticorrupción y el nuevo régimen de responsabilidades de los servidores públicos. México: USAID y Ethos.

Evans, P. (2007). El Estado como problema y como solución. En Acuña, C. (Comp.), Lecturas sobre el Estado y las politicas públicas: Retomando el debate de ayer para fortalecer el actual. Buenos Aires: Ministerio de Modernización del Gobierno de Argentina.

Klitgaard, R. (1998). Healing sick institutions. En Borner, S. y Paldam, M. (Eds.), The political dimension of economic growth. Londres: Macmillan.

Merino, M. (2013). La captura de los puestos públicos. Revista Mexicana de Ciencias Políticas y Sociales, LVIII (219), 135-156. 
México (2015). Ley General del Sistema Nacional Anticorrupción. Diario Oficial de la Federación.

Montes, P. (2019). El uso y generación de big data para combatir la corrupción en compras públicas: el caso de Chile, Colombia y México. Ponencia presentada en el XXIV Congreso Internacional del CLAD sobre la Reforma del Estado y de la Administración Pública, 12-15 de noviembre, Buenos Aires, Argentina.

Montes de Oca, L. B. (2014). ¿Innovaciones democráticas? Análisis del Consejo Consultivo de telecomunicaciones en México. Revista Mexicana de Sociología, 76, 287-320.

O'Donnell, G. (2008). Algunas reflexiones acerca de la democracia, el Estado y sus múltiples caras. XIII Congreso Internacional del CLAD sobre la Reforma del Estado y de la Administración Pública, 7-4 de noviembre, Buenos Aires, Argentina.

Olvera, A. (2009). La participación ciudadana y sus retos en México. Un breve estudio del desarrollo de la cultura y de las instituciones participativas y diagnóstico de su problemática actual, con propuestas para hacer funcionales las instancias de participación democrática. México: Secretaría de Gobernación.

Pinto, A. y Flisfisch, A. (2011). Presentación. En Pinto, A. y Flisfisch, A. (Coords), El Estado de ciudadanía: transformaciones, logros y desafíos del Estado en América Latina en el siglo XXI. Santiago: CEPAL, AECID.

. (2011). Transformaciones, logros y desafíos: Democracia, Ciudadanía y Estado. En Pinto, A. y Flisfisch, A. (Coords), El Estado de ciudadanía: transformaciones, logros y desafíos del Estado en América Latina en el siglo XXI. Santiago: CEPAL, AECID.

Pozsgai, J. (2015). Low-level corruption tolerance: An action-based approach for Peru and Latin America. Journal of Politics in Latin America, 7 (2), 99-129.

Sandoval, I. (2015). Enfoque de la corrupción estructural: poder, impunidad y voz ciudadana. Revista Mexicana de Sociología, 78 (1), 119-152.

. (2016). Corrupción y desafíos organizacionales en un mundo de asociaciones público-privadas. Gestión y Política Pública, 
XXV (2), 365-413.

Solaz H., De Vries C. E. y De Geus R. A. (2019). In-group loyalty and the punishment of corruption. Comparative Political Studies, 52 (6), 896-926.

Somuano, M. (2010). Las organizaciones civiles: Formación y cambio. En Loaeza, S. y Prud'homme, J. (Coords.), Los grandes problemas de México. Tomo XIV. México: El Colegio de México.

Tamayo, S. (2016). Espacios y repertorios de la protesta. Ciudad de México: Colofón y Universidad Autónoma Metropolitana.

Uvalle, R. (2018). Restricciones del Sistema Nacional Anticorrupción. Análisis de su diseño institucional. Ciudad de México: UNAM y La Biblioteca.

Recibido: 05-02-2019

Aceptación de la versión final: 14-06-2019 